\title{
VOZES DA MEMÓRIA: A SUPRALITERATURA SVETLANA ALEKSIÉVITCH
}

VOICES OF MEMORY: THE SUPRA-LITERATURE SVETLANA ALEKSIÉVITCH

Júlia de Campos Lucena*

RESUMO: A escritora bielorrussa Svetlana Aleksiévitch, vencedora do prêmio Nobel de Literatura em 2015, inaugura uma nova estética literária - um novo gênero em que autor e coletividad dividem a autoria de um "romance mosaico". Seus livros são compostos de breves histórias particulares, monólogos reflexivos e testemunhos coletivos de momentos tão extremos da experiência humana que só convencem porque sabemos reais. Trata-se da realidade enquanto gênero literário. Pretende-se, Tra posta por Svelana a patir da obra Vozes de Tchernóbil; proposta por Svetlana a partir da obra Vozes de Tchernobil, refletir sobre como ela toca o modelo historiográfico proposto po teóricos como Walter Benjamin e Dominick Lacapra; além de elaborar, brevemente, o gênero literário que dá suporte a esse empreendimento, e que se pretende inaugural na estética do testemunho: o Romance de Vozes.

PALAVRAS-CHAVE: Svetlana Aleksiévitch; memória; trauma.
* decampos.julia@gmail.com

Graduada em Licenciatura em Letras - Língua e Literaturas de Língua Portuguesa, Lingua Francesa e Literaturas de Língua Francesa na Universidade Federal do Rio Grande do Sul. Mestranda na área de Estudos da Literatura, especialidade Literatura, Sociedade e História da Literatura. É bolsista CAPES de mestrado na Universidade Federal do Rio Grande do Sul, com início em agosto de 2018.

ABSTRACT: Belarussian writer Svetlana Aleksiévitch, Nobel laureate in 2015, opens up a new literary aesthetic: a new genre in which author and collectivity share the authorship of a "mosaic novel". Her books are composed of private stories, reflective monologues, and collective testimonies of so extremes moments of human experience that they only convince because we know them to be real. It is the reality as a literary genre. The aim of this paper is to analyze this literary reworking of memory proposed py svetlana from the book Voices from Tchernobil refle how it touct on how it touches the historiographical model proposed by theorists such as Walter Benjamin e Dominick Lacapra; and it briefly elaborates the literary genre that supports this endeavor, and which is intended to inaugurate the aesthetics of witnessing: the Genre of Human Voices.

PALAVRAS-CHAVE: Svetlana Aleksiévitch; memory; trauma. 


\section{INTRODUÇÃO}

Passaram-se vinte anos desde a catástrofe, mas até hoje me persegue a pergunta: eu sou testemunha do quê, do passado ou do futuro?

Svetlana Alexiévitch, Entrevista da autora consigo mesm

A catástrofe tem esse curioso potencial de inverter estruturas e virar do avesso quem atinge. Isso foi, precisamente, o que aconteceu ao mundo no século XX. As bases sobre as quais repousava a longa tradição europeia ruíram sob catástrofes políticas, huma nas, econômicas e ambientais. O ser huma no foi exposto ao seu avesso e não se reconheceu no que viu. Seu potencial latente para a brutalidade - consideravelmente subestimando até então - encontrou no progresso não um freio, mas um propulsor. Tecnologia, ideologia e brutalidade re sultaram na industrialização do genocídio e em guerras cujo potencial letal a meaça todos os lados da disputa. Depois da catástrofe, o abismo. Tudo precisou ser reavaliado desde o seu fundamento, a começar pelo que se passou: o que acontecera à civilização? Como escrever sobre esses eventos? Como escrever sobre um passado que, por ser trauma, é também presente? Frente à a mplitude da experiência traumática das catástrofes do século $\mathrm{XX}$, o modelo historicista precisou ser revisto. A história monumentalista de foco economista, interessada nas grandes ações e nos grandes eventos do Estado, mantém vazios que as milhares de testemunhas desses eventos estão dispostas a preencher. A suposta neutralidade do historiador já não se sustenta. Tampouco a pretensão de uma história universal.

A experiência da barbárie cava vazios que dissimulam o trauma, mas a memória traz para o centro da análise histórica uma dimensão subjetiva que a preenche de significados e possibilita o processo de luto e recuperação. Cabe, muitas vezes, à literatura dar espaço para as reminiscências que resinificam o passado, no presente.

A pequena Bielorrússia, no leste europeu, conta com uma intraduzível história de catástrofes que desa fia a historiografia. Durante o século XX, não houve cidadão nesse pequeno país da União Soviética que tenha logrado esquivar-se do conta to direto com a catástrofe. Como contar a história de um país que, durante Segunda Guerra Mundial, perdeu um terço do seu povo? Que logo na sequência sofreu a fome, a crise econômica, e o despotismo de um regime autoritário? Que foi a vítima mais diretamente afetada do maior acidente atômico da história humana? A obra de Svetlana Aleksiévith nos aponta uma alternativa. 
Svetlana nasceu na Ucrânia em 1948, mas viveu desde a infância na Bielorrússia. Ela é uma das "filhas da Vitória", faz parte da geração que nasceu dos vencedores - afinal, a Rússia saiu vitoriosa da Segunda Guerra Mundial. Contudo, muitos dos vencedores na URSS se despediram do conflito sem pai, mãe, irmãos ou parentes quaisquer, todos eles mortos no front por doenças, pelo frio, pela fome ou assassinados em massa pelos nazistas em suas aldeias.

"O que aconteceu com o ser humano ali? O que ele viu e entendeu? A respeito da vida e da morte como um todo. E, por fim, a respeito de si mesmo" (ALEKSIÉVITCH 2016, p. 62). Essas são as perguntas que a escritora Svetla na Aleksiévitch tenta responder em A guerra não tem rosto de mulher (1985) e nos demais livros que compõem a coletânea intitulada "Vozes da Grande Utopia". São eles: As últimas testemunhas, lançado em 1985, que recupera a memória daqueles que sobreviveram à Segunda Guerra quando crianças; A guerra não tem rosto de mulher, do mesmo ano, que traz o rela to das soldadas soviéticas que lutaram na Segunda Guerra; Os meninos de Zinco, de 1887, sobre a guerra Afegã-soviética; Vozes de Tchernóbil, de 1997, que reúne diversas testemunhas e vítimas do maior desastre tecnológico do século XX que afetou, sobretudo, a Bielorrússia; e o mais recente: O fim do homem soviético, de 2013, que traz relatos de cidadãos que observam o fim de sua nação. Juntas, suas obras recuperam as vozes descartadas pela grande narrativa do Império Soviético.

O que resta da jovem soviete que voltou da guerra aos 21 anos? E da que ficou, mas perdeu pais, irmãos e não conseguiu casar, pois não havia sobrado homens com quem noivar? E das crianças que sobreviveram aos pogroms? Como se sentiram os chamados "refugiados atômicos”, evacuados das regiões próximas a Tchernóbil, de quem ninguém queria se aproximar? E por que eles insistem em voltar para os campos conta minados pela radiação para viver, para plantar e colher o que comem? Para buscar uma memória, isto é, objetos do seu passado que agora causam câncer? Que tipo de guerra foi essa em que o inimigo se escondia no céu azul, na grama verde, na safra generosa da estação? Quem foi o soviético e quem ele é agora? Quem são estes homens e mulheres que sobreviveram à grande revolução, à guerra, ao totalitarismo, à radiação e o que eles têm a contar sobre seu tempo e a humanidade?

O objeto de Svetlana é a vida singela dos pequenos indivíduos esquecidos pela história oficial, em cujos álbuns de família imagens da guerra dividem espaço com fotos 
das núpcias e de netos recém-nascidos. A experiência do mundano abre a narrativa histórica para a pluralidade de verdades antes ocultas. E Svetlana faz dessa narrativa uma justaposição de reminiscências que inaugura uma nova estética de testemunho coletivo, reescreve a crônica da catástrofe, e contribui com uma inteiramente nova perspectiva do fazer historiográfico, documental e literário.

No presente texto, apresento o texto Vozes de Tchernóbil e desenvolvo, a partir dele, algumas reflexões sobre a obra de Svetlana, que contribuem para a discussão historiográfica e literária dedicada aos temas da construção de memória cultura, testemunho e barbárie. Orientam minhas reflexões os textos de Lévi-Strauss, Dominick Lacapra e Walter Benjamin, além das leituras deste último por Gagnebin e Seligmann-Silva.

\section{CATÁSTROFE DA CONSCIÊNCIA: NOVO \\ PARADIGMA HISTORIOGRÁFICO}

No século $\mathrm{XX}$, as bases sobre as quais repousava a longa tradição europeia ruíram em ca tástrofes políticas, humanas e econômicas. O ser humano, que há pouco vivera o auge de sua "maioridade" e iluminação, enfrentava agora seu extremo obscuro. O século em que predominaram valores de igualdade e fraternidade foi sucedido pelo século que sistematizou o genocídio. Entre 1914 e 1991, o período de uma geração, mais homens foram mortos pelo próprio homem do que jamais na história. Não apenas os conflitos se tornaram infinitamente mais fa tais devido ao avanço tecnológico das armas de guerra (o evento da bomba atômica é um ponto sem retorno), ta mbém as ideologias se mostraram mais letais, assassinas e persuasivas do que nunca, apoiando-se no desenvolvimento das ciências.

Depois da catástrofe, o abismo. Tudo precisou ser reavaliado desde o seu fundamento, a começar pelo que se passou: o que acontecera à civilização? De que maneira? Por quê? Como escrever sobre um passado que, por ser trauma, é ta mbém presente?. A pergunta da qual resulta toda a obra de Walter Benja min, exigiu resposta nas décadas seguintes: que tempo é este que vivemos?

Frente à a mplitude da experiência traumática das catástrofes do século XX, o modelo historicista precisou ser revisto. A história monumentalista de foco economista, interessada nas grandes ações e nos grandes eventos do Estado, ajuda a estabelecer uma memória repleta de vazios. Frente a um evento testemunhado por milhares, a suposta neutralidade do historiador já não se sustenta, ta mpouco a pretensão de uma história universal. Fez-se 
urgente compreender a história e apropriar-se dela. Não para evitar que a catástrofe volte a acontecer, mas por saber que ela se repetirá, inúmeras vezes, enquanto a cicatriz traumática não for exposta. A experiência da barbárie cava vazios que dissimulam o trauma. Cabe às humanidades, sobretudo à história e à literatura, preencher esses vazios com memória, para que se possa dar início ao processo de luto e recuperação.

Para Lévi-Strauss (1969, p. 286), "mesmo uma história que se diz universal ainda não é mais que uma justaposição de algumas histórias locais, dentro das qua is (e entre as quais) os vazios são muito mais numerosos que os espaços cheios." E, nos vazios da história monumentalista, mantém-se em estado de latência o trauma.

Mas como escrever sobre um momento da nossa história que constitui um grande trauma coletivo do qual o eu-pesquisador, enquanto tal, e enquanto homem ou mulher no mundo pós-Auschwitz, faz parte? Dominick LaCapra alerta os historiadores para o que chama de "enga noso efeito de objetividade":

Este engañoso 'efecto de objetividad' debe diferenciarse de un defendible modo de objetividad que se alcanza por medio de una resistencia alerta teóricamente a las tendencias proyectivas o acomodaticias y del intento de enfrentar críticamente el problema de nuestra relación con el pasado. En realidad, un efecto de objetividad puede ser la compañía de una tendencia oculta a poner en acto tendencias proyectivas $\mathrm{o}$ acomodaticias en el momento mismo en que se objetiva el pasado. (LACAPRA, 2008, p. 85)

Ou seja, visando uma narrativa histórica de um discurso neutro - alienado de seu contexto de produção o historiador tende a dissimular sua presença no texto. O efeito de objetividade consequente é, no entanto, enganoso, pois rejeitando a discussão, ele dá espaço para a movimentação de tendências ocultas, as quais Lacapra classifica como tendências de projeção ou de acomodação. O que faz com que a subjetividade do historiador se manifeste, invariavelmente, mesmo que de modo abstruso, é o fenômeno da transferência.

A projeção do eu-historiador no fazer historiográfico é inevitável. Contudo, ele pode reagir a esse problema metodológico de duas maneiras: assumindo uma postura de identificação com o objeto - o historiador tenta transpor o passado para o futuro, reiterando zonas de esquecimento e de lembrança irrefletidamente -, ou tentando dominar seu objeto por completo - ele domestica o passado em nome de um discurso neutro. Ambas são 
problemáticas, posto que tentam resolver por completo o problema, isto é, tentam apagar do texto uma questão que é sua constitutiva: a negociação entre historiador e objeto. Em uma escrita não negociada, aspectos do processo histórico que está sendo historicizado podem se manifestar no texto, mantendo zonas de memória no esquecimento.

A constatação de que é impossível fazer história blindado dos processos de transferência não resulta na diminuição dessa como ciência; pelo contrário, revaloriza sua atividade:

A consciência de que a fabricação do texto-história implica procedimentos diversos de transferência pode ajudar a trazer para o primeiro pla no o "eu" historiador. De modo que o texto-história se possa transmutar em percurso do pensar, que expõe a representação histórica em suas estratégias narrativas. Não mais se ocultam os procedimentos aproximadores: o texto-história se entende como ponto de vista que se expõe em seus próprios caminhos de elaboração; assim, se apresenta como lugar da crítica. O que não implica objetividade, ou "distanciamento indistanciado"; o historiador se move dentro dos preconceitos (CHARBEL TEIXEIRA, 2003, p. 7).
Para LaCapra, já que a transferência é inevitável, a solução seria desenvolver uma negociação das relações transferenciais com o objeto de estudo, o que significa trazer ao plano do texto o "eu-historiador", de modo que o leitor possa acompanhar não um relato equivocada mente objetivo e neutro, mas um caminho de análise traçado pelo historiador em sua relação com seu objeto de pesquisa.

Da mesma forma, a literatura precisa negociar sua relação com o objeto histórico que está estetizando, pois ela corre o risco de, ao estetizar, fetichizar. A memória cultural, que abarca os ditos e os não-ditos da memória, mantém o trauma coletivo em latência. A produção cultural pode tanto expô-lo para que se possibilite a recuperação daquela memória e o luto da experiência, ou mantê-lo abstruso na consciência, de modo a possibilitar seu retorno sintomático. $\mathrm{O}$ paradoxo ao qual chega mos é duas naturezas, um trata propriamente da forma desse discurso: como narrar uma experiência inenarrável; e outro que trata do movimento de toda uma disciplina, a saber, do saber historiográfico. Walter Benjamin nos acompanha em ambas as discussões, primeiro, quando comenta em O Narrador, texto de 1936, sobre o mutismo pós-traumático e o declínio da narrativa, que, antes de um fim, é o sinal de uma reinvenção: a língua sobrevive, 
mas exige ser reinventada. E, segundo, quando em Teses sobre o conceito da história, seu texto testa mento, escrito em 1940, ele sugere que "articular o passado não significa conhecê-lo 'como ele de fato foi"', isto é, em termos absolutos e essencialistas, pelo contrário, "significa apropriar-se de uma reminiscência, tal como ela rela mpeja no momento de um perigoso".

$\mathrm{Na}$ esteira do que afirma Lévi-Strauss sobre a história, quando escreve que:

Cada episódio de uma revolução ou de uma guerra se resolve numa multidão de movimentos psíquicos e individuais [...] Cada canto do espaço contém uma multidão de indivíduos, dos quais cada um totaliza o devir histórico de uma maneira não comparável às outras; para um só desses indivíduos cada momento do tempo é inesgotavelmente rico de incidentes físicos e psíquicos que desempenham cada um o seu papel em sua totalização. (LEVIS-STRAUSS, 1969, p. 285),

Walter Benja min propõe uma história que dê conta desta multidão de movimentos individuais oprimidos seja por um fazer histórico totalizante, seja pelo fascismo (ou outras variantes de governos autoritários), que, segundo Lowy (2010),
Representa, para os oprimidos, o perigo supremo, o maior a que já foram expostos na história: a segunda morte das vítimas do passado e o massacre de todos os adversários do regime. A falsificação, em escala sem precedentes, do passado, e a transformação das massas populares em instrumento das classes dominantes. (Ebook)

Walter Benja min propõe uma forma muito particular de relação com o passado. No lugar de uma memória de "a ntiquário" ou "a rquivista", que compõe, linearmente, uma somatória de fatos, Benjamin propõe um passado que se relacione com o presente e esteja em constante transformação. Novas configurações do presente possibilitam nossas compreensões do passado, e esse se converte, para Benjamin, em objeto em constante reconstrução de si mesmo e do presente, motivando uma perspectiva crítica e aguçada que não se conforma com a ideia do progresso ininterrupto. Benjamin conclui esta que é a tese de número VI, fala ndo sobre o potencial do historiador de "despertar no passado as centelhas da esperança". Esperança, essa, encontrada a partir da relevância que ele pode dar às lutas individua is que, mesmo as fracassadas, ressignificam a luta; e a esperança, que se converte em força política, de salvar os mortos de uma segunda morte: o apagamento de sua memória. 
Nesse sentido, a literatura de Svetlana, fruto de seus esforços em recuperar a memória do povo soviético, parecem consolidar-se como a realização das propostas benja minianas de relação com o passado. A escrita polifônica do romance de vozes abre, na história, um espaço de escuta para das reminiscências de uma nação que já não existe.

\section{ROMANCE DE VOZES: A ESTÉTICA DA TRAGÉDIA}

Jornalista de formação, Svetlana tem sua obra comumente identificada como jornalismo literário ou literatura documental. Mas, para a autora, é romance. Um romance cuja forma estética se moldou a partir das exigências do nosso tempo: um tempo que tem urgência em narrar e compreender, e que exige que aprenda mos a ouvir.

Em seu discurso na cerimônia de premiação do Nobel de Literatura, em 2015, ela defende o trata mento literário de seu texto:

Ouvi mais de uma vez e ainda ouço que isso não é literatura, que é documento. Mas o que é literatura hoje? Quem pode responder? Vivemos mais rápido que antes. O conteúdo rompe a forma. Ele a quebra e modifica. Tudo extravasa das margens: a música, a pintura e, no documento, a palavra escapa aos limites do documento. Não há fronteiras entre o fato e a ficção, um transborda no outro. Mesmo a testemunha não é imparcial. Ao narrar, o homem cria, luta com o tempo assim como o escultor com o mármore. Ele é um ator e um criador. (ALEKSIÉVITCH, 2016, p. 373).

O Romance de Vozes, gênero consistentemente elaborado ao longo de sua produção, é estruturado a partir de monólogos; coros; conversas de cozinha; ruídos da rua, do transporte público; vozes solitárias; destaques do noticiário; entrevistas da autora consigo mesma. Um romance mosaico. Mas, como um álbum de fotografias ou uma curadoria artística, Svetlana não é um receptáculo passivo de histórias. Ela reordena simbolicamente o real, e as centenas de testemunhos agrupam-se em sua sólida narrativa de frases curtas e impactantes.

A arte e o mundo se tornaram multifacetados. A experiência da pós-modernidade nos permite transitar mais livremente entre as fronteiras disciplinares. $\mathrm{O}$ documento interessa à arte na medida em que nos aproxima da realidade que captura enquanto preserva o original. A arte amplia a expressão da realidade e lhe dá forma. $\mathrm{O}$ romance passa a ser compreendido não com uma forma apriorística, mas como estrutura adaptável 
que materializa conscientemente o advento de uma nova temporalidade fragmentada e descontínua. Sem o trabalho artístico de Svetlana, há realidade, mas não há linguagem. Os testemunhos, enquanto conjunto, comunicam através da forma artística do Romance de Vozes.

Walter Benja min sugere que o historiador confronte o objeto histórico enquanto mônada: não há progressão linear, ou tempo homogêneo, há um momento saturado de tensões, de histórias e de vidas. Podemos pensar o Romance de Vozes como tal: várias pequenas histórias, tensionadas ao seu extremo, que habitam o passado e o presente. E dentro de cada uma, a totalidade do processo histórico.

Para compor Vozes de Tchernóbil, Svetlana ouviu mais de setecentas vítimas do desastre. Famílias evacuadas, bombeiros e esposas de bombeiros, liquidadores - aqueles que voltavam às áreas de contaminação para exterminar o que havia restado de vida não humana -, soldados, cientistas, médicos, pessoas que insistem em continuar residindo em zonas proibidas. Eles desejavam testemunhar. Querem contar suas verdades, pois "estão morrendo, e ninguém lhes perguntou de verdade sobre o que aconteceu" (p.38). Falam na esperança de compreender: "eu recordei... para recobrar a verdade daqueles dias e dos nossos sentimentos. Para não esquecer como mudamos" (ALEKSIÉVITCH, 2016, p.283). Sua busca está em capturar, precisamente, o que Lévi-Strauss, já mencionado, chamou de "multidão de movimentos psíquicos e individuais" e devires históricos.

Essa literatura de testemunho coletivo comporta, simulta neamente, três momentos na rrativos distintos: a experiência da barbárie, que traça diversos caminhos, mas chega ao leitor com a força de um grito; o testemunho, pois o texto nunca nos deixa esquecer de que este é um esforço em direção ao impossível; e, por fim, o próprio a to de escrita, quando a autora evoca a primeira pessoa e insere autor, leitor e testemunho no tempo histórico do presente. Implicando agente histórico, historiador e leitor no processo de recuperação histórica.

\section{TCHERNÓBIL: CRONNICA DO FUTURO}

Quando explodiu um dos quatro reatores da Central Elétrica Atômica de Tchernóbil, em Prípiat, na Ucrânia, na noite do dia 26 de abril de 1986, a quantidade de radionuclídeos liberados na atmosfera superou em cinco vezes a dose estimada como fatal. Desde que o planeta Terra se tornou habitável pela espécie humana, nunca foram detectados em sua superfície doses tão elevadas de radiação. 
Os bombeiros que trabalharam para controlar o fogo do reator nas primeiras horas após a explosão receberam doses tão altas que, no início da manhã, estavam todos hospitalizados com queimaduras letais. Todos morreram dentro de poucos dias. Segundo dados do governo ucraniano, em torno de 600 mil pessoas trabalharam na área nos dias que se seguiram à explosão. Trinta anos depois, apenas 5\% da equipe de resgate e limpeza continua viva e saudável. A população precisou ser evacuada com urgência, deixando tudo para trás e, ainda hoje, o perímetro de proteção da usina se estende por um de raio de 30 quilômetros.

A nuvem de poeira tóxica liberada se espalhou em poucas horas. Em uma semana, a nuvem tóxica já havia chegado a diversos pontos da Europa Central, do norte da África e até mesmo da Ásia. Sua presença foi constatada em todo o mundo. A Bielorrússia, um país rura com uma população de 10 milhões de habitantes, que faz fronteira com a Ucrânia, recebeu $70 \%$ da radiação devido às condições climáticas do dia do acidente.

Quando Tchernóbil explodiu, criou-se uma realidade paralela que a consciência humana era incapaz de compreender. Trata-se de um evento inédito na história do mundo, mas que nos empobrece em experiência narrável.
Construímos uma tecnologia, um patrimônio científico que expandia nossa concepção de mundo, mas que reinava sozinho, pois a experiência não o vinculava a nós. Os curie, os rems, os roentgen são inimigos que não podiam ser assimilados pela consciência humana.

Na noite de 26 de abril de $1986 \ldots$ Em apenas uma noite nos deslocamos para outro lugar da história. Demos um salto para uma nova realidade, uma realidade que está acima do nosso saber e acima da nossa imaginação. Rompeu-se o fio do tempo... O passado de súbito surgiu impotente, não havia nada nele em que pudéssemos nos apoiar; e no arquivo onipotente (assim acreditávamos) da humanidade, não se encontrou a chave que abria a porta. Mais de uma vez ouvi naqueles dias: 'Não encontro palavras para expressar o que eu vi e vivi'; 'Ninguém antes me contou nada parecido'; 'Nunca li nada semelhante em livro algum, nem vi algo assim em filme algum'. Entre o momento em que aconteceu a catástrofe e o momento em que começaram a falar dela, houve uma pausa. Um momento de mudez. E todos se lembram dele... (ALEKSIÉVITCH, 2016, p. 41)

Para Walter Benjamin, a História é a experiência narrada que, no encontro com a cultura, forma a tradição. Mas Tchernóbil foi a ruptura com a tradição. Ele deslocou o homem do tempo e da história. "Eu me sinto 
impotente.", diz um dos personagens-testemunhas, "há cultura antes de Tchernóbil e nenhuma cultura depois de Tchernóbil” (ALEKSIÉVITCH, 2016, p. 283).

Havia apenas medo para exportar - e a indústria cultural fetichista aproveitou-se larga mente disso, Tchernóbil produziu um sem-fim de produtos que exploravam o bizarro, o sobrenatural e o pastiche do horror que dele proveio. Documentos que só fazia m aumentar o alhea mento da experiência e dos seus sobreviventes.

O homem se surpreendeu, não estava preparado para isso. Não estava preparado como espécie biológica, pois todo o seu instrumental natural, os sentidos constituídos para ver, ouvir e tocar, não funcionava... Os sentidos já não serviam para nada os olhos, os ouvidos e os dedos já não serviam, não podiam servir, porque a radiação não se vê, não tem odor nem som. É incorpórea. Passamos a vida lutando e nos preparando para a guerra, tão bem a conhecía mos, e, de súbito, isso. A imagem do inimigo se transformou. Surgiu diante de nós um outro inimigo... Inimigos... que tocavam a relva ceifada, o peixe pescado, a caça aprisionada. As maçãs. [...] As pessoas mais velhas, ao serem evacuadas e ainda sem perceber que isso seria para sempre, olhavam para o céu e diziam: "O sol está brilhando, não se vê fumaça nem gás. Não se escutam tiros. Como isso pode ser uma guerra? No entanto, devemos nos tornar refugiados”. (ALEKSIÉVITCH, 2016, p. 44 e 45).

Fechados em zonas contaminadas pelo governo; nas alas de quarenta pelos hospitais; no leste mundo pelo ocidente: os gulags de Tchernóbil foram resgatados por Svetlana que deu nova linguagem a um povo que, mesmo emudecido, deseja comunicar: "Eu quero testemunhar, isso aconteceu há dez a nos e todo dia se repete comigo. Não sou escritor, não saberia como contar... Mas sou testemunha” (p. 65).

Para ilustrar melhor a obra, escolhi uma pequena história, que comporta em si muito do horror que os sobreviventes de Tchernóbil compartilham. Svetla na abre espaço para que ouçamos a voz de "Nikolai Fomítch Kalúguin, um pai”, que deixou de ser homem para se tornar "um homem de Tchernóbil. Um a nimal raro!". Sua capítulo chama-se: Monólogo sobre toda uma vida escrita nas portas.

"Vivía mos na cidade Prípiat. Nessa mesma cidade que hoje o mundo inteiro conhece. Não sou escritor, não saberia como contar... Mas sou testemunha. Aconteceu assim... Vamos ao início..."(ALEKSIÉVITCH, 2016, p. 65). Nikolai foi evacuado junto com sua família no terceiro 
dia após a explosão, enqua nto o reator ainda queimava. Deixou para trás tudo: sua casa, roupas, pertences, até mesmo o gato teve de ser abandonado. De tudo, e todos, emanava radiação.

Dois anos depois, Nikolai voltou para a zona contaminada, contra riando as ordens militares e arriscando ser a utuado. Ele ia buscar a porta de sua casa. A porta era o elemento central de sua família, um registro não convencional de sua memória. Nela o pai marcou a altura de Nikolai conforme ele ia crescendo, e nela ele próprio marcou a altura dos filhos conforme estes iam crescendo. Na ocasião da morte do pai, foi nela que se velou o defunto; e agora ele volta buscá-la para velar a filha que morria em decorrência da radiação.

A porta da casa era, para essa família, seu passado e seu futuro, sinônimo de vida e de morte. Mas depois da explosão, ela deixou de ser um objeto ordinário da vida comum. Era agora um objeto radioa tivo sem recuperação que carecia apenas de abandono e isolamento. Nikolai não compreende como é possível pedir a alguém para que abandone sua história tão radicalmente, recuperá-la tem um custo extremo, que ele está disposto a pagar, pois já não há muito que possa perder.
Quando o mundo deixa de ser familiar para se tornar estranhamento, a impossibilidade de compreender e comunicar desespera, mas não ta nto qua nto não se encontrar ouvido sequer capaz de ouvir a mudez que resta.

É preciso compreender, porque vamos viver com isso. [...] Eu quero testemunhar, a minha filha morreu por culpa de Tchernóbil. E ainda querem nos calar. Dizem que a ciência ainda não comprovou, não há banco de dados. É preciso esperar cem anos. Mas a minha vida humana... Ela é ainda mais curta. Eu não vou esperar. Anote. Anote ao menos que a minha filha se chamava Kátia. Katiúchenka. Morreu aos sete anos (ALEKSIÉVITCH, 2016, p. 66)

Svetlana rompe com o isolamento do terror quando se posiciona como a escuta ativa de testemunhas que reposicionam o evento catastrófico na construção identitária de um país. O sentimento de impotência diante dos acontecimentos é equivalente ao esforço de lembrar e registrar. Talvez não seja nunca possível compreender Tchernóbil, mas é preciso dizê-lo e é preciso ouvir dizê-lo. O incompreensível precisa ser pronunciado, pois apenas a linguagem oferece um caminho de libertação às consciências rendidas pelo trauma. 


\section{TESTEMUNHA TAMBÉM AQUELE QUE}

\section{NÃO VAI EMBORA}

Mas a linguagem não funciona fora do par enunciativo. A enunciação de um eu compreende como parte fundamental a presença de um outro. No testemunho, o invivível e o inenarrável cruzam a linguagem e refundam-se nela para alcançar um terceiro não implicado que, talvez, será capaz de aliviar a carga do testemunho apenas por existir longe dessa experiência e garantir essa possibilidade de ser.

Gagnebin (2006), quando trata a respeito da potência deste terceiro elemento no testemunho (sendo os primeiros o torturado e o torturador), relembra o sonho narrado por Primo Levi em É isto um homem?. No sonho, ele está de volta ao lar, tem sua irmã e a migos ao redor muitos deles. Ele sente-se feliz por estar de volta e por ter tanta coisa para contar, mas logo percebe que todos estão indiferentes a sua narração, a té que se levantam, e vão embora. Deixo-o continuar:

Nasce então, dentro de mim, uma pena desolada, como certas mágoas da infância que ficam vagamente em nossa memória; uma dor não temperada pelo sentido da realidade ou a intromissão de circunstâncias estranhas, uma dor dessas que fazem chorar as crianças. Melhor, então, que eu torne mais uma vez à tona, que abra bem os olhos; preciso estar certo de que acordei, acordei mesmo.

O sonho está na minha frente, ainda quentinho; eu, embora desperto, continuo, dentro, com essa angústia do sonho lembro, então, que não é um sonho qualquer; que, desde que vivo aqui, já o sonhei muitas vezes, com pequenas variantes de a mbiente e detalhes. Agora estou bem lúcido, recordo ta mbém que já contei o meu sonho a Alberto e que ele me confessou que esse é também o sonho dele e o sonho de muitos mais; talvez de todos. Por quê? Por que o sofrimento de cada dia se traduz, constantemente, em nossos sonhos, na cena sempre repetida da narração que os outros não escuta m? (LEVI, 1988 p. 85 e 86$)$.

Primo Levi sente-se condenado, em seu sofrimento, a uma violenta mudez pelos ouvidos surdos dos demais. É ao não encontrar interlocutor que a narração do trauma se torna impossível. Para Gagnebin (2006), ta mbém testemunha aquele que não vai embora, que ouve, a té o fim, a narração insuportável do outro,

Não por culpabilidade ou por compaixão, mas porque somente a transmissão simbólica, assumida apesar e por causa do sofrimento indizível, somente essa retomada reflexiva do passado pode nos ajudar a não repeti-lo 
infinitamente, mas a ousar esboçar uma outra história a intentar o presente. (GAGNEBIN, 2006, p. 57).

A obra de Svetlana parece responder a este anseio por escuta. No processo de composição de seus livros, ela ocupa - fisica mente - o espaço do interlocutor a té então ausente; no processo de escrita - solitário e distanciado - ela opera a transposição desse lugar ao seu narrador, e este, por sua vez, demanda ao leitor que faça o mesmo: que se permita ser ele também testemunha das experiências narradas. O efeito desse movimento é causa da brutalidade do texto: não é permitido ao leitor distanciar-se da realidade, pelo contrário, exige-se que ele se afunde nela. O leitor sente um arrebata mento tão profundo, tão pungente, que, não raro, referem-se ao livro como "uma experiência terrível de leitura". O que eu traduzo como uma experiência do terrível, na leitura.

Para Svetlana, depois da barbárie, a litera tura não tem mais o direito de inventar: "Deve-se mostrar a verdade como ela é. Exige-se uma 'supraliteratura', uma literatura que esteja além da literatura. É a testemunha que deve falar.” (ALEKSIÉVITCH, 2016, p. 372). Se Fla ubert era o homem-pena, para quem a ficção era o único mundo possível, ele fez-se a mulher-ouvido: seus esforços residem em escutar a literatura do real.

\section{REFERÊNCIAS}

ALEKSIÉVITCH, Svetlana. Vozes de Tchernóbil: crônica do futuro. São Paulo: Companhia das Letras, 2016.

BENJAMIN, Walter. Experiência e pobreza. In: Obras escolhidas: magia e técnica, arte e política. Vol. 1. São Paulo: Brasiliense, 1985.

O narrador. Considerações sobre a obra de Nikola Leskov. In: _. Magia e técnica, arte e política. São Paulo: Brasiliense, 1985.

\section{Teses sobre o conceito da história. Ebook.}

CHARBEL TEIXEIRA, Felipe. Representação histórica: retórica da alteridade, domesticação da existência. In: ANPUH - XXII SIMPÓSIO NACIONAL DE HISTÓRIA, 2003, João Pessoa. Disponível em: http://www.encontro2014.rj.anpuh. org/resources/anais/anpuhnacional/S.22/ANPUH.S22.230.pdf Acesso em: 01.08.2019.

ACAPRA, Dominick. Representar el Holocausto. Historia teoría, trauma. Buenos Aires: Prometeo, 2008. 
LÉVI-STRAUSS, Claude. O pensamento selvagem.

Campinas, SP: Papirus, 1969.

LUCIC, Ana. Uma conversa com Svetlana Aleksiévitch

[S. I.], 26 abr. 2016. Disponível em: http://historico.

blogdacompanhia.com.br/2016/04/uma-conversa-com-

svetlana-alexievich/. Acesso em: 01.08.2019.

LOWY, Michel. Aviso de incêncio: uma leitura das teses

"Sobre o conceito da história". Ebook: 2005.

GAGNEBIN, Jeanne Marie. Lembrar esquecer escrever. São Paulo: Editora 34, 2006.

NOBEL de Literatura, jornalista Svetlana Aleksiévitch se encontra com leitores em São Paulo. [S. I.]: Companhia das Letras, 2016. Disponível em: https://www.youtube.com/ watch?v=BIrQA9qqmW0. Acesso em: 01.08.2019.

SELLIGMAN-SILVA, Márcio. Testemunho e a política da

memória: $\mathbf{O}$ tempo depois das catástrofes. Proj. História,

São Paulo, (30), p. 71-98, jun. 2005.

Recebido em: 16/112019

Aceito em: 24/08/2020

EM TESE

BELO HORIZONTE

v. 26

N. 2

MAIO-AGO. 2020

LUCENA. Vozes da memória: a supraliteratura svetlana aleksiévitch 